\title{
Using Family-Focused Garden, Nutrition, and Physical Activity Programs To Reduce Childhood Obesity: The Texas! Go! Eat! Grow! Pilot Study
}

\author{
Erica C. Spears-Lanoix, MA,' E. Lisako J. McKyer, PhD, MPH,' Alexandra Evans, PhD, MPH, \\ William Alex Mclntosh, $\mathrm{PhD}^{3}$ Marcia Ory, PhD, MPH, ${ }^{4}$ Lisa Whittlesey, MS, \\ Alice Kirk, MPH, Deanna M. Hoelscher, PhD, LD, RD, and Judith L. Warren, PhD ${ }^{6}$
}

\section{Abstract}

Background: The TEXAS! GROW! EAT! GO! (TGEG) randomized, control trial is a 5-year study to measure the impact of a nutrition and gardening intervention and/or physical activity (PA) intervention on the weight status of third-grade students. This article describes the results of the pilot study to test the feasibility of two interventions and test the measures to be used in the main trial.

Methods: The pilot study was conducted in one school with third-grade students and their parents or guardians. The Junior Master Gardner (JMG) and Walk Across Texas (WAT) interventions were implemented over a 5-month period in three third-grade classrooms during spring 2012. The respective interventions focused on improving healthy eating and PA behaviors of children and their families. Baseline and immediate post-test data were collected from students and parents/guardians to measure four child, four parent, and four parent-child interaction behaviors. Process data regarding implementation were also collected from teachers and school administration.

Results: Forty-four students and 34 parents or guardians provided both pre- and post-test data. Paired-sample $t$-tests showed statistically significant changes in student knowledge, vegetable preferences, vegetable consumption, and home food availability (all $p<0.05)$. At baseline, participants' weight status categories included $57 \%$ obese, $10 \%$ overweight, and $31 \%$ normal weight. Postintervention, weight status categories included 39\% obese, $16 \%$ overweight, and normal $45 \%$. Data collected from teachers indicated high levels of implementation fidelity.

Conclusions: Implementation of both interventions occurred at a very high fidelity level, which led to positive changes in BMI status, and several dietary and PA behaviors. Although the pilot study indicated feasibility of the two interventions for school implementation, results guided revisions to the TGEG program and its survey instruments.

\section{Introduction}

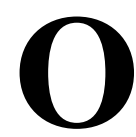
ver the past 30 years, childhood obesity rates have doubled among children and quadrupled in adolescents. ${ }^{1-3}$ Though there is evidence of these rates plateauing in recent years, the widespread decline hoped for has yet to happen. ${ }^{4-6}$ Additionally, poorer, publicly insured black and Hispanic children remain disproportionately represented in overweight and obese statistics. ${ }^{6-9}$

Although causes of obesity are multifactorial and complex, most researchers agree that physical inactivity and poor dietary patterns, including insufficient vegetable consumption, are two behaviors that contribute to the development of overweight and obesity. ${ }^{10-13}$ For children, these

\footnotetext{
'Department of Health and Kinesiology, ${ }^{3}$ Department of Sociology, ${ }^{5}$ Department of Horticultural Sciences, ${ }^{6}$ Family and Consumer Sciences, Texas A\&M University, College Station, TX.

${ }^{2}$ UTHealth School of Public Health, University of Texas, Houston, TX.

${ }^{4}$ School of Public Health, Texas A\&M Health Sciences Center, College Station, TX.

${ }^{7}$ School of Public Health, University of Texas, Austin, TX.
}

Spears-Lanoix et al. (c) 20I5; Published by Mary Ann Liebert, Inc. This Open Access article is distributed under the terms of the Creative Commons License (http://creativecommons.org/licenses/by/4.0), which permits unrestricted use, distribution, and reproduction in any medium, provided the original work is properly credited. 
behaviors are greatly influenced by their school and home environments. ${ }^{14-16}$ Research has found that as availability and accessibility of fruits and vegetables (F\&Vs) in the home increases, $\mathrm{F} \& \mathrm{~V}$ consumption increases as well. ${ }^{17-21}$ Additionally, because schools serve students of all races and socioeconomic backgrounds, these institutions are viewed as one of the most viable platforms for positively impacting disparity rates and improving childhood overweight and obesity statistics at large. ${ }^{15,22}$ Improving family and community involvement has the potential to increase the impact of existing school-based efforts aimed at positively impacting child overweight and obesity rates. ${ }^{23-26}$

Recent studies indicate that successful child obesity prevention efforts, particularly those in low-income communities, require coordinated efforts and consistent messages from schools, communities, and families for optimal effectiveness. ${ }^{27-30}$ Few models, however, have focused on achieving this coordinated effect in a manner that could be sustained at the local level and disseminated to other locations. ${ }^{31}$ Further, limited rigorous studies had been developed using the Cooperative Extension Programs (Extension). Determining whether promising Extension family-focused programs can increase the efficacy of existing programs on childhood obesity will build an evidence base for national school-Extension collaborations, in which Extension serves as a diffusion mechanism for programs and provides an infrastructure for the institutionalization of family-focused childhood obesity programs within the school/community setting.

The Texas A\&M AgriLife Extension Services-which employs experts in health, nutrition, and horticulturecollaborated with academic partners from other disciplines within the A\&M system, and the University of Texas School of Public Health to develop the TEXAS! GROW! EAT! GO! (TGEG) study. TGEG is an innovative "Integrated Research-Extension" project funded through the USDA National Institute for Food and Agriculture. The study's primary aim is to assess the efficacy of enhancing existing school-based efforts with two family-focused, experiential gardening, nutrition, and physical activity (PA) Extension programs on the prevalence of child overweight and obesity. Social cognitive theory tenets support each program component. Moreover, external project advisers, including national food and nutrition experts, reviewed and provided feedback on the selected curriculum components for cultural relevance and effectiveness with limited-resource families and youth.

For the full TGEG study, one coordinated school health program, Coordinated Approach to Child Health $(\mathrm{CATCH})$, was enhanced with two interventions, the Junior Master Gardner Program (JMG) and Walk Across Texas (WAT). Since 1987, CATCH has been implemented as a elementary school-community intervention to combat childhood obesity through the promotion of healthy food choices and increased PA. ${ }^{32}$ Currently, CATCH is implemented in 7000 US schools. ${ }^{32}$ JMG is a youth horticulture classroom curriculum used to teach students about "plant needs and people needs," including health and nutrition concepts. ${ }^{33}$ WAT "is a program designed to establish regular PA as a lifetime habit in students." 34 The refinements and combinations of these three interventions into a coordinated, comprehensive approach to childhood overweight and obesity reduction is the innovative basis of TGEG.

Using a randomized, controlled study (RCT) design, the TGEG study will evaluate different combinations of these 1-year interventions in 28 Title 1 elementary schools (1600 student-parent pairs), within four regions of Texas. The study focuses on child and parent/guardian behavioral factors that are strongly related to childhood obesity. The four child behaviors include increased $\mathrm{F} \& \mathrm{~V}$ consumption, decreased sugar-sweetened beverage (SSB) consumption and increased water consumption, increased PA, and decreased sedentary activity. The four parent/guardian behaviors include increased access and availability of F\&Vs at home, limited availability of SSBs at home, providing PA opportuinities for childrens and limiting children's sedentary activity. The four child and parent interaction behaviors include gardening together, snacks and meals together, dinners eaten together, and PA together.

The 5-month pilot study described in this article was implemented with third-grade students and their parents/ guardians at one school to test the feasibility and effectiveness of the interventions and further test the child and parent research surveys preceding the full RCT. All third-grade students, without a previous chronic disease diagnosis that could impact weight, were eligible for participation in the study. During the pilot, three teachers in one Title 1 school implemented CATCH, JMG, and WAT with the students in their third-grade classes. Students' experiential learning included building a class garden, growing seven vegetables, tasting and rating each vegetable, raw, and participating in vegetable recipe tasting, demonstrated by Extension staff. Take-home recipes in English and Spanish were used to promote family adoption. Teachers also engaged their classrooms in the 8-week WAT PA competition. These activities included family bonus miles, waling Bingo, and class activity breaks. This article describes and reports on the outcomes of the TGEG pilot study.

\section{Methods}

After obtaining institutional review board approval from the research institutions and the school district, the TGEG pilot study was conducted in one Texas elementary school with a study population of 122 third-grade students and their parents. The pilot study took place during the spring semester of 2012, in three classrooms, using the JMG and WAT interventions. JMG was implemented in the study population for the entire 5-month semester; whereas WAT was implemented for 8 weeks within the same 5-month study period. Data were collected through pre and post student and parent/guardian surveys (see Table 1). Student height/weight and body composition data were also collected at baseline and postintervention. 


\begin{tabular}{|c|c|c|c|c|}
\hline & \multicolumn{2}{|c|}{ Dietary behaviors } & \multicolumn{2}{|c|}{ Physical activity } \\
\hline & Fruits and vegetables & Sugar-sweetened drinks & Physical activity & Sedentary time \\
\hline Parent & & & $\begin{array}{l}\text { 个 Opportunities for } \\
\text { their child }\end{array}$ & $\downarrow$ Opportunities for their child \\
\hline Child & $\uparrow$ Consumption & $\downarrow$ Consumption & $\uparrow$ Frequency & $\downarrow$ Frequency \\
\hline Parent $\times$ Child & $\uparrow$ Preparing foods together & $\uparrow$ Eating meals together & $\uparrow$ Gardening together & $\uparrow$ Physical activity together \\
\hline
\end{tabular}

\section{Measures and Protocol}

Surveys were developed using validated questions from the School Physical Activity and Nutrition study, Gimme 5, Eat Your Way to Better Heath (an instrument developed by Purdue), and other surveys. Additional survey questions were developed specifically for this study, in an effort to ensure appropriateness in the context of the study population. Both the student and parent surveys were translated into Spanish and then back into English to ensure correct translations. To ensure that the surveys were at appropriate literacy levels and that the items within the survey were understandable to the target population, both the student and parent surveys were tested using cognitive testing methods.

Student surveys were administered orally by research assistants. All research assistants were trained by the University of Texas' School of Public Health's research coordinator, utilizing standardized protocol to ensure consistency of training. A PowerPoint presentation of all vegetables, in a variety of forms, were presented along with the survey to increase students' recognition of the vegetable. The questions were designed to capture demographic information and information on specific behaviors (see Table 1) and knowledge. Parent surveys were sent home to parents through the school, by their children. The surveys contained 60 primarily multiple-choice items measuring demographic data, general knowledge of vegetables, cooking experience, and specific behaviors (see Table 1).

Sociodemographic variables. Students were given multiple-choice items to report their sex, age, and grade. Parents were asked to provide more detailed demographic information than the students, for additional context and a more robust analysis. Accordingly, the parent survey included 20 questions regarding demographics including age, race, sex, marital status, work status, languages spoken in the home, level of education, and child's participation in the school's free and reduced lunch program.

Vegetable preference and consumption. To measure vegetable preference and consumption, students were asked whether they had eaten a vegetable (response options "yes," "no," or "I don't know"), followed up with a query of whether they liked the vegetable depicted in the presentation (response options "no," "yes, a little," or "yes, a lot"). Emoticons, or pictorial emotion icons, ac- companied the item response options surrounding preference to aid student comprehension of the survey response options. Students' vegetables consumption frequencies were also assessed by a series of "Yesterday, I ate" questions targeting specific vegetables (i.e., those likely to be part of the gardening aspect of the project). Table 2 provides examples of these items as well as example items from other domains. Table 3 details the number of items used to develop aggregate scores this and other domains.

Food availability. The parent survey included items to assess in-home availability of various food and beverage options. Example items included: "Last week, did you have $100 \%$ juice in your home?" with response options of "never," "some of the time," "most of the time," and "all of the time." Items assessed included F\&V juices and SSBs, as well as vegetable in various forms (e.g., canned, fresh, and frozen). Items for each domain were combined to create aggregate (scale) scores (see Table 3).

Physical activities. As illustrated in Table 1, we measured various aspects of PA. For student reports of their family activities, participating students were asked to respond to multiple-choice questions and by various Likert scales. For example, students were asked to describe adults in their families by responding to the statement "spend time teaching you how to play sports and be active" on a 5-point Likert scale with the options "never," "once in a while," "sometimes," "a lot of times," and "all of the time." Students were also asked to respond to questions such as, "In the past year, have you planted seeds or plants in a vegetable garden with members of your family?" and asked to select either "yes" or "no." Similar to food availability, the PA items were also aggregated into scales (see Table 3 ). PA was also recorded and reported by the teachers of each class participating in the pilot study. Teachers registered their classes in WAT to recorded class level data for the number of miles walked per week.

Nutrition and health knowledge. To assess students' baseline knowledge and knowledge gains, students were asked questions about healthy living. Questions such as, "How much of your lunch or dinner plate should be vegetables?" were asked, followed by four pictograms depicting different portion sizes followed by wording to describe the picture such as "quarter (1/4)," "half (1/2)," 


\section{Table 2. Examples of Items Used from Questionnaires for TGEG Pilot}

\begin{tabular}{|c|c|c|}
\hline Source & Domain and example items & Response scale \\
\hline $\begin{array}{l}\text { Student-about } \\
\text { self }\end{array}$ & $\begin{array}{l}\text { Example of vegetable and sugar sweetened beverage items } \\
\text { Yesterday, did you eat any other vegetables like tomatoes, asparagus, } \\
\text { red cabbage, cauliflower, cucumbers, mushrooms, green or red bell peppers, } \\
\text { eggplant, or celery? } \\
\text { - No, I didn't eat any of these vegetables yesterday } \\
\text { - Yes, I ate these vegetables I time yesterday } \\
\text { - Yes, I ate these vegetables } 2 \text { times yesterday } \\
\text { - Yes, I ate these vegetables } 3 \text { times yesterday }\end{array}$ & Ordinal \\
\hline Parent & $\begin{array}{l}\text { Last week did you have fresh vegetables in your home? } \\
\text { Soft drinks or sugar sweetened beverages in your home? }\end{array}$ & $\begin{array}{l}\text { Likert } \\
\text { Never - All of the time }\end{array}$ \\
\hline $\begin{array}{l}\text { Source } \\
\text { student-about } \\
\text { self }\end{array}$ & $\begin{array}{l}\text { Examples of physical activity items } \\
\text { About every day I do light physical activity } \\
\text { Yesterday, did you do any moderate or vigorous physical activities } \\
\text { for about } 30 \text { minutes (about the time it takes to watch a cartoon) DURING THE DAY? }\end{array}$ & $\begin{array}{l}\text { Dichotomous } \\
\text { Yes/No }\end{array}$ \\
\hline $\begin{array}{l}\text { Source } \\
\text { about parents } \\
\text { and family }\end{array}$ & $\begin{array}{l}\text { In the past year, have you planted seeds or plants in a vegetable garden } \\
\text { with members of your family? } \\
\text { Please tell us how often adults in your family play sports and are active with you? }\end{array}$ & $\begin{array}{l}\text { Dichotomous } \\
\text { Yes/No } \\
\text { Likert } \\
\text { Never - All of the time }\end{array}$ \\
\hline Parent & $\begin{array}{l}\text { During the last seven days, on how many days did you do vigorous physical activities } \\
\text { like heavy lifting, digging, aerobics or fast bicycling? } \\
\text { How much time did you usually spend doing vigorous physical activities } \\
\text { on one of those days? }\end{array}$ & $\begin{array}{l}\text { Ratio } \\
\text { Open Ended }\end{array}$ \\
\hline $\begin{array}{l}\text { Student-about } \\
\text { self }\end{array}$ & $\begin{array}{l}\text { Examples of sedentary behavior items } \\
\text { Yesterday, how many hours did you sit watching TV, DVD's, or movies } \\
\text { AWAY FROM SCHOOL? } \\
\text { - I didn't spend any time watching TV yesterday } \\
\text { - Less than I hour } \\
\text { - I-2 hours } \\
\text { - } 2-4 \text { hours } \\
\text { - More than } 4 \text { hours }\end{array}$ & Ordinal \\
\hline Parent & After work, I am too tired to be physically active with my child & $\begin{array}{l}\text { Likert } \\
\text { Strongly Agree - } \\
\text { Strongly Disagree }\end{array}$ \\
\hline
\end{tabular}

"three fourths (3/4)," and "whole (all)." Students were also asked whether things such as protein, carbohydrates, fat, and so on, were examples of nutrients found in food and asked to select either "yes," "no," or "I don't know."

Health status. Parent participants were asked to provide information about their personal health, including several chronic conditions often associated with obesity, such as heart disease and type 2 diabetes. Parents were also asked about genetic disorders, such as cystic fibrosis and sickle cell anemia. For each condition listed, respondents were asked to respond "yes" or "no." For each disease, the respondent answered "yes" to, they were also asked to respond "yes" or "no" to the taking medication for the condition.

Anthropometric information. Height and weight data were collected pre- and postintervention for each student participant using standardized protocols. ${ }^{34,35}$ Data were collected twice for reliability by pairs of trained project staff or research assistants during school site visits. Per- spective Enterprise (Model PE-AIM-10; Perspective Enterprise, Portage, MI) stadiometers were used to measure student height, and the Tanita scale (model BWB-800S; Tanita Corporation of America, Inc., Arlington Heights, IL) was used for measurement of student weight and body composition. BMI categories for the students were calculated using the $\mathrm{CDC}$ growth charts. ${ }^{36}$

Implementation of interventions. Third-grade teachers completed a survey designed to capture teacher health behaviors and perceptions of effectiveness with regard to the lessons used within the study. Teachers were asked to respond using a 4-point Likert scale, where a rating of 1 was considered "not at all successful" and a rating of 4 was considered "very successful." Teachers also completed a weekly electronic survey about each lesson's timing and ease of implementation. Three teachers, the school principal, assistant principal, and parent support specialist were also interviewed by TGEG staff to provide recommendations for improvement. 


\begin{tabular}{|c|c|}
\hline Domain & No. of items \\
\hline \multicolumn{2}{|l|}{ Food and beverage related } \\
\hline Child knowledge scores & 9 \\
\hline Child vegetable preferences & 2 \\
\hline Child vegetable attempts & 20 \\
\hline Child vegetable (only) consumption & 4 \\
\hline Child fruits and vegetables consumption & 26 \\
\hline Child sugar-sweetened drinks intake & 2 \\
\hline Child Water intake & 1 \\
\hline Parental provision of vegetable options & 9 \\
\hline \multicolumn{2}{|l|}{ PA } \\
\hline Child preference for PA & 4 \\
\hline Child PA frequency & 23 \\
\hline Parent and child joint gardening & 5 \\
\hline
\end{tabular}

PA, physical activity.

\section{Results}

Sixty-two students and parents enrolled in the pilot study. Parental consent could not be obtained for 60 of the 122 students in the original sample; accordingly, those students were not included in the study results. Data cleaning was also performed, by automatic database features and manual reviews, to evaluate outliers and completeness of data. At the conclusion of the pilot study, 44 students and 34 parents completed both baseline and postsurveys. Of the survey respondents, $95 \%$ were selfreported as low income; $63 \%$ Hispanic, $13 \%$ black, $11 \%$ white, and $13 \%$ other. Thirty-two percent $(32 \%)$ of parents were enrolled in the Supplemental Nutrition Assistance Program; $10 \%$ in the Special Supplemental Nutrition Program for Women, Infants, and Children.

Body mass index classification. Students' weight statuses at baseline were categorized as $57 \%$ obese, $10 \%$ overweight, $31 \%$ healthy weight, and $2 \%$ underweight. Post- intervention weight status was as follows: $39 \%$ obese, $16 \%$ overweight, and $45 \%$ healthy weight. No students were categorized as underweight in postintervention (see Fig. 1).

Physical activity. Student PA was measured at the class level through the WAT curriculum. Week 1 measurements were approximately 4 miles per student. By week 8 , student PA increased to 9 miles per week. The number of PAs performed by students each week increased from 11 to 13 . The number of hours students spent performing PAs with parents each week also increased slightly from 4.45 to 4.63 hours.

Child and parent outcomes. Paired $t$-tests were performed on student and parent focused outcome variables and revealed promising changes. As detailed in Table 5, child knowledge, vegetable preferences, and vegetable consumption increased between baseline and postintervention. Student preferences for gardening compared to other activities increased from $26 \%$ preintervention to $38 \%$ postintervention. In addition, there was an increase in the mean amount of the time students spent gardening. In terms of parent variables, significant differences were found for home availability of vegetables.

Teachers in the study population were asked to evaluate components of the JMG curriculum used in the TGEG study for feasibility and perceived effectiveness. The average rating was 3.6, which would be categorized between "mostly" and "very" successful based on the 4-point Likert scale provided. Four components were assessed. The teachers rated the vegetable tasting component the highest, with a mean score of 3.9. Gardening and outdoor activities received an overall rating of 3.6. The mean score for journaling was 3.5. Classroom activities were rated as 3.3. Teachers also commented on the high level of student engagement in all activities and made recommendations on each lesson and activity for JMG and WAT.

\section{Discussion and Conclusions}

Consistent with previous research, the TGEG pilot study showed positive changes. There were significant changes in students' weight statuses, diets, and rates of PA. ${ }^{28,38}$ Students also increased vegetable preferences and nutrition knowledge levels. ${ }^{39}$ On average, students consumed more vegetables, and greater varieties, postintervention and

\section{Table 4. Tracking Physical Activity through WAT}

\section{Number of miles walked by week}

\begin{tabular}{l|c|c|c|c|c|c|c|c|c}
\hline Class & Week I & Week 2 & Week 3 & Week 4 & Week 5 & Week 6 & Week 7 & Week 8 & Total miles walked \\
\hline I & 92 & 138 & 139 & 250 & 216 & 154 & 216 & 216 & 142 I \\
\hline 2 & 15 & 25 & 55 & 120 & 200 & 250 & 200 & 250 & 1115 \\
\hline 3 & 79 & 144 & 151 & 145 & 135 & 138 & 155 & 160 & 1107 \\
\hline
\end{tabular}

Data reported on the class level, with approximately 20 students in each class (62 students total).

WAT, Walk Across Texas. 


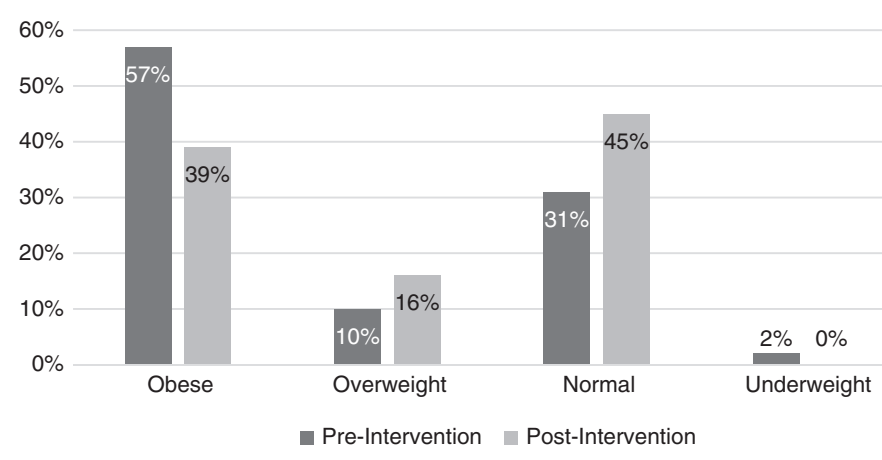

Figure 1. Student weight status.

reported preferences for gardening increased. ${ }^{14,17,40}$ Additionally, students reported increased PA and limited sedentary behavior. ${ }^{40}$ There was also a reported increase in vegetable availability in the home by parents participating in the study. The average teacher rating for components of the program was between "mostly" and "very" successful.

The pilot study findings are limited, in part, because there was no control group utilized for comparison. The lack of a control group is customary, however, for pilot studies. Additionally, the study's sample size was small, owing to high student mobility and difficulties obtaining completed parental consent forms. It should be noted also that it cannot be assessed whether the large decrease in obesity within the study population can be attributed solely to the TGEG intervention. However, we argue that the purposes of pilot studies are to ensure intervention feasibility, and therefore the limitations expressed are not of major concern at this time. Subsequent implementation of the full intervention, using a randomized control design, is currently underway and addresses concerns regarding internal validity, sample size, and generalizability.

Additional study limitations exist and should be noted. The study's retention rates were less than optimal, with $70.96 \%$ of students and $54.83 \%$ of parents. These numbers are not entirely surprising, however, based on the transient nature of the community surrounding the school used in the pilot study. The results presented utilize comparisons between the initial study sample and those that completed the study, so the groups are not matched exactly. Exact matching will be utilized in the full study. PA was measured at the class level and by participant self-reports. Actual accelerometer reports would have been preferable. Regarding dietary intake, parent reports were used, but a 24-hour dietary recall would have been preferable.

The feasibility of the combined programs for the larger RCT was supported by the pilot study findings. However, based on teacher and expert reviewer feedback, modifications were made. The student survey was shortened. For example, many of the students had difficulty responding to the survey question regarding ethnicity. This question was removed from the child's survey and added to the parent survey. PowerPoints depicting the vegetables described were developed to accompany the student survey. Additional staff, four to five members in total, were added during survey administration to help answer student questions. The consent process was streamlined. Forms were combined, where prudent, to reduce the amount of paperwork required of parents. The number of lessons included in the intervention were increased - six vegetables were added and the implementation was expanded to 14 weeks. Additional student journal activities and family

Table 5. Result of t-Tests on Outcome Variables

\begin{tabular}{|c|c|c|c|c|c|c|c|}
\hline \multirow[b]{2}{*}{ Food and beverage-related } & \multicolumn{2}{|c|}{ Pre } & \multicolumn{2}{|c|}{ Post } & \multirow[b]{2}{*}{$\mathbf{T}$} & \multirow[b]{2}{*}{$d f$} & \multirow[b]{2}{*}{ Sig. (2-tailed) } \\
\hline & $\mathbf{M}$ & SD & $\mathbf{M}$ & SD & & & \\
\hline Child knowledge scores & 3.12 & $1.4 \mathrm{I}$ & 4.36 & 1.70 & 4.16 & 32 & $0.00 *$ \\
\hline Child vegetable preferences & 18.07 & 9.77 & 20.43 & 9.93 & 2.41 & 29 & $0.02 *$ \\
\hline Child vegetable attempts & 3.58 & 2.28 & 4.00 & 2.32 & 0.85 & 30 & 0.40 \\
\hline Child vegetable (only) consumption & 13.03 & 5.31 & 15.42 & 5.25 & 3.98 & 30 & $0.00 *$ \\
\hline Child fruits and vegetables consumption & 7.46 & 2.56 & 8.43 & 3.97 & 1.94 & 40 & 0.06 \\
\hline Child sugar-sweetened drinks intake & 1.75 & 1.84 & 2.05 & 1.78 & 1.41 & 43 & 0.17 \\
\hline Child water intake & 1.15 & 0.80 & 1.18 & 0.81 & 0.23 & 39 & 0.82 \\
\hline Parental provision of vegetable options & 16.76 & 5.00 & 21.00 & 5.78 & 2.37 & 28 & $0.02 *$ \\
\hline \multicolumn{8}{|l|}{ Physical activity } \\
\hline Child preference for PA & 3.42 & 0.98 & 3.34 & 9.67 & 0.49 & 37 & 0.63 \\
\hline Child PA frequency & 11.08 & 6.31 & 13.21 & 6.10 & 1.61 & 23 & 0.12 \\
\hline Parent \& child joint gardening & 4.60 & 3.27 & 4.89 & 4.03 & 0.63 & 41 & 0.53 \\
\hline
\end{tabular}

Note $M=$ Mean and $S D=$ Standard Deviation.

* Significant at $p<.05$. 
stories, coupled with a modified WAT newsletter in both English and Spanish, were included to increase dosage and connections to home. We are confident that these changes will help to strengthen the overall program and its impact on the larger study population.

\section{Acknowledgments}

This project was supported by the Agriculture and Food Research Initiative (grant no.: 2011-68001-30138) from the USDA National Institute of Food and Agriculture, Integrated Research, Education and Extension to Prevent Childhood Obesity, A2101.

The authors acknowledge Texas A\&M University, Texas A\&M AgriLife Extension Services, and the University of Texas School of Public Health.

This material is based upon work that is supported by the National Institute of Food and Agriculture, USDA under award number 2011-68001-30138.

\section{Author Disclosure Statement}

No competing financial interests exist.

\section{References}

1. CDC. Adolescent and school health. Available at www.cdc.gov/ healthyyouth/obesity/facts.htm Last accessed September 7, 2014.

2. Ogden CL, Carroll MD, Kit BK, et al. Prevalence of childhood and adult obesity in the United States, 2011-2012. JAMA 2014;311:806-814.

3. National Center for Health Statistics. Health, United States, 2011: With special features on socioeconomic status and health. US Department of Health and Human Services: Hyattsville, MD, 2012.

4. Wabitsch M, Moss A, Kromeyer-Hauschild K. Unexpected plateauing of childhood obesity rates in developed countries. $B M C$ Med 2014;12:17.

5. Ogden CL, Carroll MD, Kit BK, et al. Prevalence of obesity and trends in body mass index among US children and adolescents, 1999-2010. JAMA 2012;307:483-490.

6. Bethell C, Simpson L, Stumbo S, et al. National, state, and local disparities in childhood obesity. Health Aff (Millwood) 2010;29:347-356.

7. Madsen KA, Weedn AE, Crawford PB. Disparities in peaks, plateaus, and declines in prevalence of high BMI among adolescents. Am Acad Pediatr 2010;126:434-442.

8. Taber DR, Stevens J, Poole C, et al. State disparities in time trends of adolescent body mass index percentile and weight-related behaviors in the United States. J Commun Health 2012;37:242-252.

9. Sails JF, Glanz K. Physical activity and food environments: Solutions to the obesity epidemic. Milbank $Q 2009 ; 87: 123-154$.

10. Al-Hazzaa HM, Abahussain NA, Al-Sobayel HI, et al. Physical activity, sedentary behaviors and dietary habits among Saudi adolescents relative to age, gender and region. Int J Behav Nutr Phys Activ 2011;8:140-154.

11. Swinbun BA, Caterson I, Seidell JC, et al. Diet, nutrition and the prevention of excess weight gain and obesity. Public Health Nutr 2004; 7:123-146

12. Ebbeling CB, Pawlak DB, Ludwig DS. Childhood obesity: Publichealth crisis, common sense cure. Lancet 2002;360:473-482.
13. Epstein LH, Gordy CC, Raynor HA, et al. Increasing fruit and vegetable intake and decreasing fat and sugar intake in families at risk for childhood obesity. Obes Res 2012;9:171-178.

14. McIntosh WA, Davis G, Nayga R, et al. Parental time, role strains, and children's fat intake and obesity. Available at http://ddr .nal.usda.gov/dspace/bitstream/10113/32790/1/CAT31012237.pdf Last accessed June 22, 2010.

15. Nihiser A, Merlo C, Lee S. Preventing obesity through schools. J Law Med Ethics 2013;42:87-94.

16. Reed SF, Viola J, Lynch K. School and community-based childhood obesity: Implications for policy and practice. J Prev Interv Community 2014;42:87-94.

17. Woodruff SJ, Hanning RM. A review of family meal influence on adolescents' dietary intake. Can J Diet Pract Res 2008;69:14-22.

18. Bois JE, Sarrazin PG, Brustad RJ, et al. Elementary schoolchildren perceived competence and physical activity involvement: The influence of parent's role modeling behaviours and perceptions of their child's competence. Psychol Sport Exerc 2005;6:381-397.

19. Coulthard H, Blissett J. Fruit and vegetable consumption in children and their mothers: Moderating effects of child sensory sensitivity. Appetite 2009;52:410-415.

20. Gross SM, Pollock EE, Braun B. Family influence: Key to fruit and vegetable consumption among fourth- and fifth-grade students. J Nutr Educ Behav 2010;42:235-241.

21. Pearson N, Biddle SJH, Gorely T. Family correlates of fruit and vegetable consumption in children and adolescents: A systematic review. Public Health Nutr 2008;12: 267-283.

22. Kraak VA, Liverman CT, Koplan JP (eds). Preventing Childhood Obesity: Health in the Balance. National Academies Press: Washington, DC: 2005.

23. Khan LK, Sobush K, Keener D, et al. Recommended community strategies and measurements to prevent obesity in the United States: Implementation and measurement guide. Centers for Disease Control and Prevention: Atlanta, GA, 2009.

24. Story M, Nanney MS, Schwartz MB. Schools and obesity prevention: Creating school environments and policies to promote healthy eating and physical activity. Milbank $Q$ 2009;87:71-100.

25. CDC. School health guidelines to promote healthy eating and physical activity. 2011. Available at www.cdc.gov/mmwr/preview/ mmwrhtml/rr6005a1.htm Last accessed October 17, 2014.

26. Fung C, Kuhle S, Lu C. From "best practice" to "next practice": The effectiveness of school-based health promotion in improving healthy eating and physical activity in preventing childhood obesity. Int J Behav Nutr Phys Activ 2012;9:27.

27. Peters LW, Widfferink CH, Hoekstra F, et al. A review of domain similarities between domain specific determinants of four health behaviors among adolescents. Health Educ Res 2009;24:198-223.

28. Hoelscher DM, Springer AE, Ranjit N, et al. Reductions in childhood obesity among disadvantaged school children with community involvement: The Travis county CATCH trial. Obesity (Silver Spring) 2010;18(Suppl 1):S36-S44.

29. Sanigorski AM, Bell AC, Kremer P, et al. Reducing obesity in early childhood: Results from Romp \& Chomp, an Australian communitywide intervention program. Am J Clin Nutr 2011;91:831-840.

30. Parmer SM, Salisbury-Glennon J, Ayala GX. Parental influences on adolescent physical activity: A longitudinal study. Int J Behav Nutr Phys Act 2007;4:3. Available at www.ijbnpa.org/content/4/1/3 Last accessed June 17, 2010.

31. Bumbarger B, Perkins D. After randomized trials: Issues related to dissemination of evidence-based interventions. J Child Serv 2009;3:55-64. 
32. CATCH USA. Why CATCH? Available at http://catchusa.org/ whycatch.html Last accessed October 19, 2014.

33. Junior Master Gardner (LMG). What is JMG? Available at http:// jmgkids.us/what-is-jmg Last accessed October 19, 2014.

34. Walk Across Texas. Walk Across Texas teachers registration guide. Available at http://walkacrosstexas.tamu.edu/PDF/wat-teachersregistration-guide.pdf Last accessed October 19, 2014.

35. Lohman TG, Roche AF, Martorell R. Anthropometric Standardization Reference Manual. Human Kenetics: Champaign, IL, 1988.

36. Lee RD, Niemans DC. Anthropometry in Nutritional Assessment, 3rd ed. McGraw-Hill, New York, 2003.

37. CDC. Clinical growth charts. Available at www.cdc.gov/ growthcharts/clinical_charts.htm Last accessed June 5, 2015.

38. Hoelscher DM, Kelder SH, Cribb PW, et al. Dissemination and adoption of the Child and Adolescent Trial for Cardiovascular Health $(\mathrm{CATCH})$ : A case study in Texas. J Public Health Manag Pract 2001;7:90-100.
39. Robinson-O'Brien R, Story M, Heim S. Impact of garden-based youth nutrition intervention programs: A review. J Am Diet Assoc 2009; 109:273-280.

40. Boyer R, Waliczek TM, Zajicek JM. The Master Gardener program: Do benefits of the program go beyond improving the horticultural knowledge of the participants? Hort Technol 2002;12:432-436.

Address correspondence to:

Erica C. Spears-Lanoix, MA

Transdisciplinary Center for Health Equity Research

Texas A\&M University

4243 TAMU

Blocker Suite 311

College Station, TX 77843

E-mail: espears@hlkn.tamu.edu 